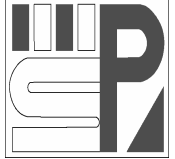

Science Press

Journal of Arid Land

2012, 4(4): 411-419

doi: 10.3724/SP.J.1227.2012.00411

jal.xjegi.com; www.chinasciencejournal.com

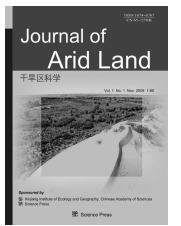

\title{
Carbon sequestration in the total and light fraction soil organic matter along a chronosequence in grazing exclosures in a semiarid degraded sandy site in China
}

\author{
YinPing CHEN ${ }^{1}$, YuQiang LI ${ }^{2 *}$, Tala AWADA ${ }^{3}$, JuanJuan $\mathrm{HAN}^{2}$, YongQing LUO \\ ${ }^{1}$ School of Environmental and Municipal Engineering, Lanzhou Jiaotong University, Lanzhou 730070, China; \\ ${ }^{2}$ Cold and Arid Regions Environmental and Engineering Research Institute, Chinese Academy of Sciences, Lanzhou 730000, China; \\ ${ }^{3}$ School of Natural Resources, University of Nebraska, Lincoln, NE 68583, USA
}

\begin{abstract}
Horqin Sandy Land is a fragile, seriously desertified region located in Inner Mongolia of China. Overgrazing is one of the primary drivers of desertification in this region. We investigated whether the establishment of grazing exclosures in areas with active sand dunes enhances soil carbon (C) sequestration and benefits soil recovery. The results showed that soil organic $C$ storage was $1.4,1.9$, and 3.5 times, and light fraction $C$ storage was 2.3, 3.2, and 4.4 times in the 100-cm topsoil after 7,12 , and 25 years of grazing exclusion, respectively, compared to the case in active sand dunes. The light fraction of soil played an important role in soil $\mathrm{C}$ sequestration, although it might not change rapidly to provide an early indication of how soil $\mathrm{C}$ is increasing in response to grazing exclusion. The results indicated that soils could potentially sequester up to $13.8 \mathrm{Mt} \mathrm{C}$ in 25 years if active sand dunes in the study area were to be protected by exclosures. This corresponds to $12.8 \%$ of the estimated carbon loss (107.53 Mt) that has been associated with desertification over the past century in the Horqin Sandy Land. Our results suggested that exclosures have the capacity to increase soil $C$ sequestration; however, decades will be required for soil $C$ to recover to historical grassland levels observed prior to desertification.
\end{abstract}

Keywords: carbon storage; overgrazing; exclosures; desertification; Horqin Sandy Land

Domestic livestock grazing in semi-natural and managed rangelands (Soderstrom et al., 2001) affects vegetation cover, soil processes, biodiversity, and ecohydrology (Ibáñez et al., 2007). While appropriate grazing intensity can benefit plant growth and species diversity, overgrazing can result in rangeland degradation and desertification (Cooper et al., 2005). In fact, overgrazing is thought to be one of the primary drivers for desertification in many arid and semiarid regions. It is generally agreed upon that grazing exclusion can benefit the restoration of ecosystem services, including soil fertility, biomass, species composition, diversity of surface fauna, eco-hydrology, and soil water-holding capacity; grazing exclusion is one of the most widely suggested option to sequester and restore soil carbon in arid and semiarid lands. Some studies, however, have argued that grazing exclusion rarely results in the restoration of soil and vegetation (Westoby et al., 1989; Laycock, 1991; Conant et al., 2005). In this study we investigated the effectiveness of exclosures in restoring soil carbon of active sand dunes along a chronosequence ranging from 0 to 25 years.

The Horqin Sandy Land $\left(42^{\circ} 41^{\prime}-45^{\circ} 15^{\prime} \mathrm{N}, 118^{\circ} 35^{\prime}-\right.$ $123^{\circ} 30^{\prime} \mathrm{E}$ ) is one of the most seriously desertified and ecologically fragile regions in China's agro-pastoral ecotone. Soil degradation and desertification in this region have resulted from several decades of overgrazing, non-manure short fallow cropping, and arbitrary land use and management that failed to take into

Received 2012-02-27; accepted 2012-05-24

*Corresponding author: YuQiang LI (E-mail: yqli1975@yahoo.com.cn) 
consideration local harsh climate and the fragility of this ecosystem. Destruction of the natural vegetation has led to widespread wind erosion and loss of soil fertility (Dregne, 1986). Historically, the Horqin Sandy Land was almost fully covered by lush natural native vegetations that provided a favorable environment for both animals and humans. However, by 2000, the area of desertification had expanded to over $50,198 \mathrm{~km}^{2}$, accounting for $47.6 \%$ of the total area (Wu, 2005). The total carbon loss from the plant-soil system due to desertification has been estimated to be 107.53 Mt during the last century (Zhou et al., 2008).

Total soil organic matter might not be the best indicator to assess changes in soil quality at these sites, as it often takes many years before significant changes are detected in the quantity and quality of soil organic matter (Hassink et al., 1997; Gong et al., 2009). However, different fractions of the soil organic matter may respond differently. For example, the light fraction organic matter, which can be isolated from soil organic matter by flotation, is a plant-like fraction with high C concentration (Tan et al., 2007) and has a relatively short turnover time in the soil (Gregorich et al., 1996). Thus, this fraction is generally considered to be a highly dynamic soil property, and may therefore provide an early indicator of management-induced changes in soil quality (Six et al., 2002; Murage et al., 2007; Bending and Turner, 2009; Wang et al., 2009).

In the present study, we aimed to (1) investigate the role of the light fraction organic matter in soil carbon sequestration, and (2) quantify carbon storage in the total soil organic matter and light fraction in the Horqin Sandy Land under long-term continuous overgrazing and livestock-exclusion treatments.

\section{Materials and methods}

\subsection{Study area}

The study was conducted at the Naiman Desertification Research Station of Chinese Academy of Sciences, Inner Mongolia, China. The station is located in the southern part of the Horqin Sandy Land near Daqintala in Naiman county of Inner Mongolia $\left(42^{\circ} 58^{\prime} \mathrm{N}\right.$, $120^{\circ} 43^{\prime} \mathrm{E} ; 385 \mathrm{~m}$ asl). The study area is characterized by sand dunes that alternate with gently undulating interdunal lowlands, with a sand deposit thickness of
20-120 m. The soil is classified as a Cambic Arenosol of sandy origin in the FAO soil classification system (FAO, 2006), and is characterized by a coarse texture and a loose structure. As a result, this type of soil is very susceptible to damage by animal disturbance and wind erosion, especially in areas with low vegetation cover.

The region has a continental semiarid monsoon temperate climate. The mean annual precipitation is $366 \mathrm{~mm}$, of which $8.3 \%$ occurs during the dormant season from November to April, and the mean annual potential evaporation is $1,935 \mathrm{~mm}$. The annual mean air temperature is $6.8^{\circ} \mathrm{C}$, with a minimum monthly mean of $-13.2^{\circ} \mathrm{C}$ in January and a maximum monthly mean of $23.5^{\circ} \mathrm{C}$ in July. The frost-free period ranges from 130 to 150 days. The mean wind speed is $4.3 \mathrm{~m} / \mathrm{s}$, with occasional occurrence of $\geq 20 \mathrm{~m} / \mathrm{s}$ gales in winter and spring, when the vegetation cover is lowest and the soil is driest. The combination of these factors makes the soils highly prone to wind erosion.

Historically, the native vegetation in the study area was dominated primarily by grass species (i.e. Stipa grandis, Leymus chinensis, and Agropyron cristatum), along with sparsely scattered woody species (i.e. $U l$ mus pumila, Populus simonii, Populus pseudo-simonii, and Quercus mongolica). The sustainable grazing intensity is estimated to be 2 to 3 sheep equivalents per hectare in the sandy rangeland of this area. However, the palatable grasses have been overgrazed and the woody species have been in large harvested for fuel over the past several decades. This poor land management has led to the reduction in vegetation cover and the degradation of soils. As a result, the area has become dominated by active sand dunes covered by annual forbs.

Extensive afforestation and livestock exclusion programs were initiated in the 1970 s to restrain the expansion of the dune areas. We selected 7-, 12-, and 25-year exclosures as our study sites to investigate the effects of exclosure on soil carbon recovery. Before livestock exclusion, the landscape was characterized by active sand dunes. For each exclosure age, we established three sites (replications). At each site, we sampled one $30 \mathrm{~m} \times 30 \mathrm{~m}$ plot. In addition, we selected three active sand dune sites (created under long-term continuous overgrazing, which we subsequently re- 
ferred to as exclosure age 0) in neighboring areas as the control. As in the exclosures, we established one $30 \mathrm{~m} \times 30 \mathrm{~m}$ plot in each of the three active sand dune sites. Thus, a total of 12 plots were established for this study. The plots faced south, and had slopes $<12^{\circ}$.

\subsection{Measurements}

Vegetation measurements were completed in August, 2009 (Table 1). We randomly established six $1 \mathrm{~m} \times 1 \mathrm{~m}$ subplots within each of the 12 plots and sampled both the aboveground litter and the live biomass. After the removal of the litter layer, soil samples were collected using a soil auger $(2.5 \mathrm{~cm}$ in diameter) from five layers: $0-10 \mathrm{~cm}, 10-20 \mathrm{~cm}, 20-40 \mathrm{~cm}, 40-60 \mathrm{~cm}$, and $60-100 \mathrm{~cm}$. We obtained these samples at 10 points from each of the six subplots. Soil samples collected from the different points within each subplot were mixed to provide a composite soil sample for each soil layer. For the determination of soil bulk density, three additional soil cores were collected in each subplot using a soil auger equipped with a stainless-steel cylinder ( $5 \mathrm{~cm}$ in both diameter and height), and bulk density was calculated for each individual soil layer (Table 2).

\subsection{Laboratory analyses}

Litter and plant biomass samples were dried at $60^{\circ} \mathrm{C}$ in a forced-air oven for $48 \mathrm{~h}$ and weighed to the nearest 0.1 g. Soil samples were air-dried and hand-sieved through a $2-\mathrm{mm}$ mesh to remove roots and other debris. A portion of each air-dried sample was ground to pass a $0.15-\mathrm{mm}$ mesh before the determination of total soil organic $\mathrm{C}$ concentration. The remaining portion was stored at room temperature for the determination of light fraction organic matter content and particle-size distribution.

A subsample of the air-dried soil was weighed and dried at $105^{\circ} \mathrm{C}$ for $24 \mathrm{~h}$ for the determination of gravimetric water content. Soil particle sizes were analyzed by the wet-sieving method using sodium hexametaphosphate as the dispersing agent (ISO, 1998). The soil samples were separated by means of a nested series of sieves with openings of 2, 0.1 , and $0.05 \mathrm{~mm}$ respectively into three fractions: coarse sand ( 2 to 0.1 $\mathrm{mm})$, fine sand ( 0.1 to $0.05 \mathrm{~mm})$, and silt + clay $(<0.05$ $\mathrm{mm})$. The total soil organic $\mathrm{C}$ concentration was determined using the $\mathrm{K}_{2} \mathrm{Cr}_{2} \mathrm{O}_{7}-\mathrm{H}_{2} \mathrm{SO}_{4}$ oxidation method of Walkey-Black (Nelson and Sommers, 1982).

Table 1 Site characteristics of active sand dunes (control plots, i.e. exclosure of age 0), and 7-, 12- and 25-year exclosures

\begin{tabular}{|c|c|c|c|c|}
\hline \multirow{2}{*}{$\begin{array}{l}\text { Exclosure age } \\
\quad \text { (year) }\end{array}$} & \multirow{2}{*}{ Dominant species } & \multirow{2}{*}{$\begin{array}{c}\text { Cover } \\
(\%)\end{array}$} & \multicolumn{2}{|c|}{ Aboveground biomass $\left(\mathrm{g} / \mathrm{m}^{2}\right)$} \\
\hline & & & Live plant & Litter \\
\hline 0 & Agriophyllum squarrosum & $3 \pm 1^{\mathrm{a}}$ & $11 \pm 5^{\mathrm{a}}$ & $4 \pm 1^{\mathrm{a}}$ \\
\hline 7 & Artemisia halodendron, Setaria viridis, Corispermum macrocarpum & $15 \pm 1^{\mathrm{b}}$ & $48 \pm 9^{b}$ & $37 \pm 9^{b}$ \\
\hline 12 & A. halodendron, Bassia dasyphylla, S. viridis, Melissitus ruthenicus, Euphorbia humifusa & $42 \pm 3^{c}$ & $103 \pm 8^{\mathrm{c}}$ & $109 \pm 16^{\mathrm{c}}$ \\
\hline 25 & $\begin{array}{l}\text { Cleistogenes squarrosa, Lespedeza davurica, Artemisia scoparia, B. dasyphylla, Salsola } \\
\text { collina, Chenopodium glaucum }\end{array}$ & $61 \pm 3^{\mathrm{d}}$ & $95 \pm 15^{\mathrm{c}}$ & $185 \pm 31^{\mathrm{d}}$ \\
\hline
\end{tabular}

Note: Means ( \pm SE) within the same column followed by different letters differ significantly at $P<0.05$.

Table 2 Soil bulk density $\left(\mathrm{g} / \mathrm{cm}^{3}\right)$ in active sand dunes (age 0 ), and 7-, 12- and 25-year exclosures

\begin{tabular}{ccccc}
\hline \multirow{2}{*}{ Soil depth $(\mathrm{cm})$} & \multicolumn{4}{c}{ Exclosure age (year) } \\
\cline { 2 - 5 } & 0 & 7 & 12 & 25 \\
\hline $0-10$ & $1.64 \pm 0.01^{\mathrm{a}}$ & $1.64 \pm 0.01^{\mathrm{a}}$ & $1.60 \pm 0.01^{\mathrm{b}}$ & $1.57 \pm 0.01^{\mathrm{c}}$ \\
$10-20$ & $1.65 \pm 0.02^{\mathrm{a}}$ & $1.66 \pm 0.01^{\mathrm{a}}$ & $1.60 \pm 0.01^{\mathrm{b}}$ & $1.59 \pm 0.01^{\mathrm{b}}$ \\
$20-40$ & $1.64 \pm 0.02^{\mathrm{a}}$ & $1.64 \pm 0.01^{\mathrm{a}}$ & $1.58 \pm 0.01^{\mathrm{b}}$ & $1.60 \pm 0.01^{\mathrm{ab}}$ \\
$40-60$ & $1.65 \pm 0.02^{\mathrm{a}}$ & $1.63 \pm 0.02^{\mathrm{ab}}$ & $1.59 \pm 0.01^{\mathrm{b}}$ & $1.61 \pm 0.03^{\mathrm{ab}}$ \\
$60-100$ & $1.64 \pm 0.01^{\mathrm{ab}}$ & $1.66 \pm 0.01^{\mathrm{a}}$ & $1.61 \pm 0.01^{\mathrm{ab}}$ & $1.60 \pm 0.02^{\mathrm{b}}$ \\
Mean & $1.65 \pm 0.01^{\mathrm{a}}$ & $1.64 \pm 0.01^{\mathrm{a}}$ & $1.60 \pm 0.01^{\mathrm{b}}$ & $1.59 \pm 0.01^{\mathrm{b}}$ \\
\hline $\begin{array}{l}\text { Note: Means }( \pm \text { SE) within the same row followed by different letters differ significantly } \\
\text { at } P<0.05 .\end{array}$ & & & &
\end{tabular}

The light fraction organic matter was extracted from the soil using the procedure described by Murage et al. (2007). An air-dried bulk soil sample of around $20 \mathrm{~g}$ was weighed into a $100-\mathrm{mL}$ centrifuge tube, followed by the addition of $80 \mathrm{~mL}$ of $\mathrm{NaI}$ at a density of $1.8 \mathrm{~g} / \mathrm{cm}^{3}$. The liquid in the tube was then swirled by hand for $30 \mathrm{~s}$, and the contents were dispersed using a probe-type sonic disrupter for $1 \mathrm{~min}$. After a deposit of $30 \mathrm{~min}$, the solution was centrifuged at $8,000 \mathrm{~g}$ for 30 min. The samples were then allowed to settle over night. The suspended light fraction material was then 
obtained from the supernatant under suction using a Whatman No. 1 filter paper, and was washed thoroughly with five aliquots of $0.01 \mathrm{~mol} / \mathrm{L} \mathrm{CaCl}_{2}$ and ten aliquots of distilled deionized water. The remaining light fraction was dried at $55^{\circ} \mathrm{C}$ for $16 \mathrm{~h}$, and then weighed and ground using an agate mortar and pestle. The light fraction dry matter content was expressed as a percentage of the total soil mass. To obtain enough light fraction for our analyses, we used three to six subsamples from each soil sample. We determined a single value of light fraction $\mathrm{C}$ concentration for all five layers combined at a given subplot. The light fraction $\mathrm{C}$ concentration was determined using the same procedure that we used for measuring the bulk soil organic $\mathrm{C}$.

\subsection{Data analysis}

The total soil organic carbon (SOC) storage and light fraction carbon (LFC) storage were calculated using the following equations:

$$
\begin{gathered}
\text { SOC storage }=\sum_{i=1}^{n}\left(C_{s i} \times B D_{i} \times H_{i}\right) \times 10, \\
\text { LFC storage }=\sum_{i=1}^{n}\left(D M_{i} \times C_{L F i} \times B D_{i} \times H_{i}\right) / 10 .
\end{gathered}
$$

Where, $C_{s i}$ is the SOC concentration $(\mathrm{g} / \mathrm{kg}), B D_{i}$ the soil bulk density $\left(\mathrm{g} / \mathrm{cm}^{3}\right), H_{i}$ the soil layer thickness (cm), $D M_{i}$ the light fraction dry matter content to the total soil mass (\%), $C_{L F i}$ the LFC concentration $(\mathrm{g} / \mathrm{kg}$ dry LF), and $n$ the number of soil layers.

Soil organic $\mathrm{C}$ concentration and light fraction dry matter content were analyzed using two-way ANOVA, with exclosure age and soil layer as the two factors. These variables and their resultant $\mathrm{C}$ storage were also analyzed using one-way ANOVA, with exclosure age as the factor. Mean separation was performed using the least-significant-difference (LSD) tests. Correlations between variables were calculated using Pearson's correlation coefficient. The statistical analysis was performed using the SPSS software version 13.5 (SPSS, Chicago, IL, USA).

\section{Results}

\subsection{Total soil organic $\mathrm{C}$ concentration}

The total soil organic $\mathrm{C}$ concentration differed significantly among exclosure ages $(F=82.6, d f=3, P<0.001)$, soil layers $(F=41.8, d f=4, P<0.001)$, and their interac- tion $(F=15.5, d f=12, P<0.001)$. In general, soil organic $\mathrm{C}$ concentration increased with increasing exclosure age and decreased with soil depth (Fig. 1). Soil organic $\mathrm{C}$ concentration in the sampled layers of the top 40 -cm soil was significantly higher $(P<0.05)$ in the 25- than in the 12- and 7-year exclosures, and the active sand dunes (age 0). There were no significant differences between the 12- and 25-year exclosures at the $40-100 \mathrm{~cm}$ soil depths. Total soil organic $\mathrm{C}$ concentration in the top $0-10 \mathrm{~cm}$ soil did not differ significantly from that in active sand dunes after 7 years of livestock exclusion. However, a significant increase $(P<0.05)$ was observed after 12 years of exclusion. There were no significant differences in the $\mathrm{C}$ concentration between the 7- and the 12-year exclosures or the active sand dunes at the $40-100 \mathrm{~cm}$ soil depths. For the combined layers of $0-100 \mathrm{~cm}$, the 25-, 12-, and 7-year exclosures had 4.6, 2.2, and 1.5 times the total soil organic $\mathrm{C}$ concentrations, respectively, relative to active sand dunes. However, this difference was not significant for the 7-year exclosure.

\subsection{Light fraction organic matter}

Similar to the total soil organic $\mathrm{C}$ concentration, the light fraction dry matter content also showed significant differences among exclosure ages $(F=18.1, d f=3$, $P<0.001)$ and soil layers $(F=18.4, d f=4, P<0.001)$, increasing with exclosure age and decreasing with soil

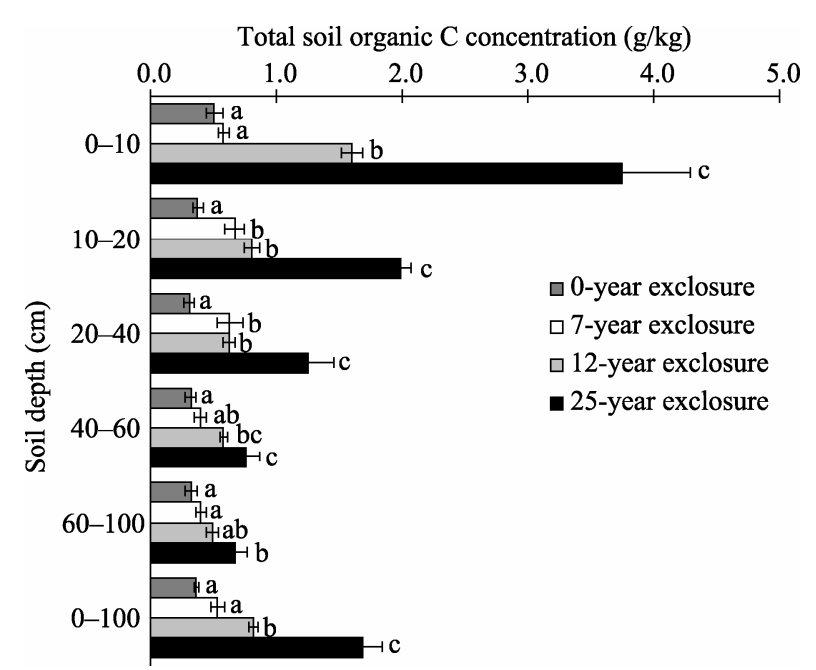

Fig. 1 Total soil organic $C$ concentration (means \pm SE) as a function of exclosure age. Bars labeled with different letters differ significantly between exclosure ages $(P<0.05$, ANOVA followed by LSD tests) at each depth. 
depth (Fig. 2). The largest difference was observed in the $0-10 \mathrm{~cm}$ soil layer. The light fraction dry matter accounted for only a small proportion $(<0.5 \%)$ of the total soil mass. For the combined layers of $0-100 \mathrm{~cm}$, the content of the light fraction dry matter was only $0.036 \%$ in the active sand dunes, but increased by 2.5 , 4.6, and 6.8 times in response to livestock exclusion for 7,12 , and 25 years, respectively. The light fraction dry matter was significantly correlated with both the total soil organic $\mathrm{C}$ concentration $\left(R^{2}=0.90, P<0.001\right)$ and the silt+clay content $\left(R^{2}=0.82, P<0.001\right)$ (Fig. 3). In addition, the light fraction organic $\mathrm{C}$ concentration was 374 times the value of total soil organic $\mathrm{C}$ in the plots with active sand dunes, compared to 282, 187, and 90 times the values in the 7-, 12-, and 25-year exclosures, respectively. However, the light fraction organic $\mathrm{C}$ concentration did not differ significantly among exclosures, or between exclosures and sand dunes (Fig. 4).

\subsection{Carbon storage}

As with the combined layers of $0-100 \mathrm{~cm}$, our results showed that the total soil organic C storages in the 7-, 12-, and 25-year exclosures were 1.4, 1.9, and 3.5 times higher, respectively, than that of active sand dunes (Table 3). The corresponding light fraction $\mathrm{C}$ storages were $2.3,3.2$, and 4.4 times the values recorded in active sand dunes (Table 3). The carbon storage in the total soil and light fraction did not differ significantly between active sand dunes and the 7-year exclosure,

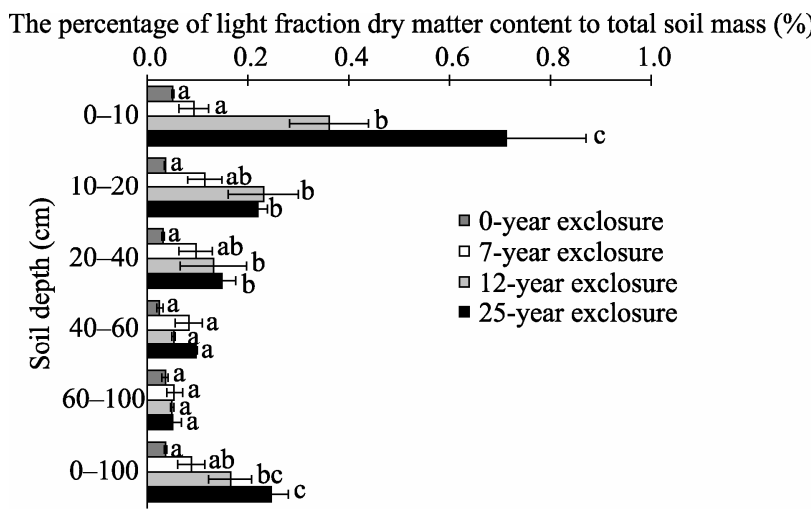

Fig. 2 Light fraction dry matter content (as a \% of the soil mass) as a function of exclosure age. Bars labeled with different letters differ significantly between exclosure ages $(P<0.05$, ANOVA followed by LSD tests) at each depth.
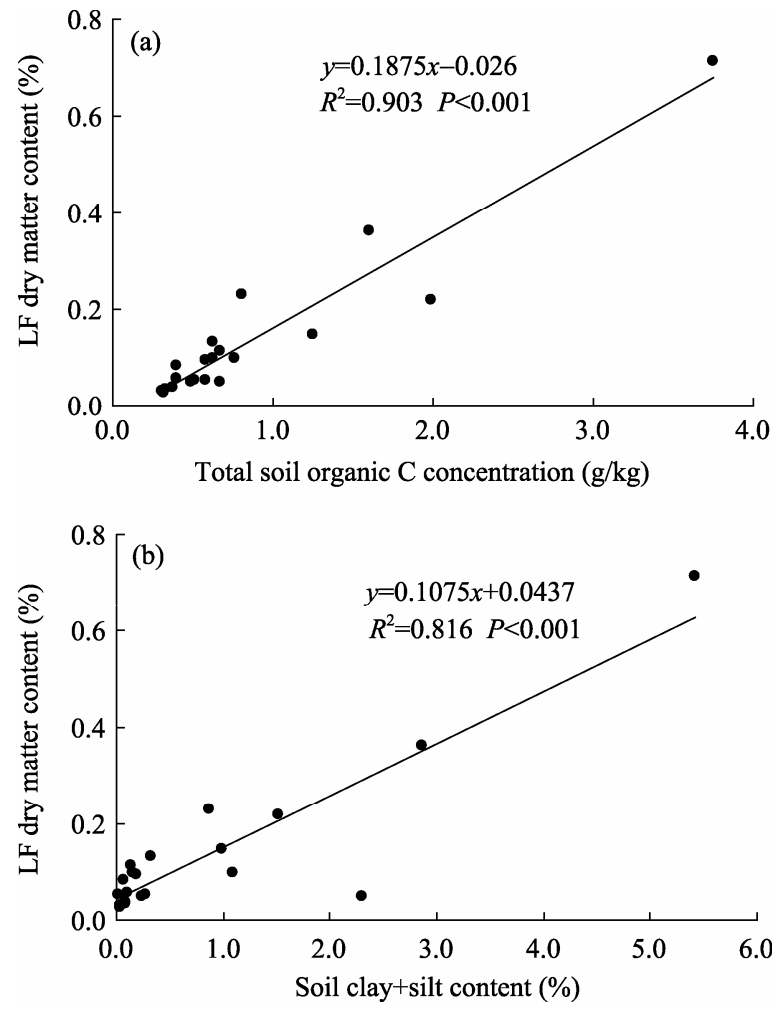

Fig. 3 Light fraction (LF) dry matter content as a function of (a) total soil organic $\mathrm{C}$ concentration and (b) silt+clay content

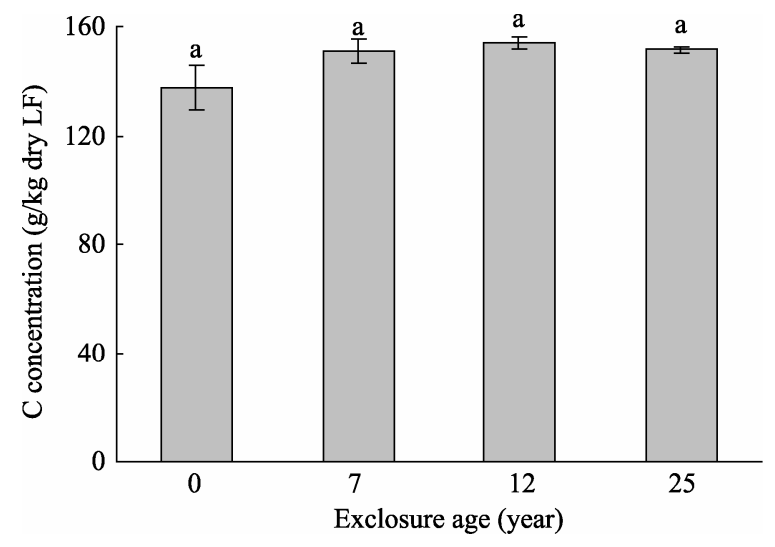

Fig. 4 Light fraction (LF) C concentration as a function of exclosure age. Bars labeled with different letters differ significantly $(P<0.05)$ among exclosure ages.

but were significantly lower than those observed in the 12- and 25-year exclosures. The contribution of the light fraction $\mathrm{C}$ to the total soil organic $\mathrm{C}$ increment was $45 \%, 36 \%$, and $21 \%$ after grazing exclusion for 7 , 12 , and 25 years, respectively ( i.e. a lower contribution of the light fraction $\mathrm{C}$ with increasing exclosure age). 
Table 3 SOC storage and LFC storage as functions of exclosure age

\begin{tabular}{cccccc}
\hline $\begin{array}{c}\text { Carbon } \\
\text { storage } \\
\left(\mathrm{g} / \mathrm{m}^{2}\right)\end{array}$ & $\begin{array}{c}\text { Soil depth } \\
(\mathrm{cm})\end{array}$ & \multicolumn{4}{c}{ Exclosure age (year) } \\
\cline { 3 - 6 } SOC & $0-10$ & $84 \pm 11^{\mathrm{a}}$ & $96 \pm 7^{\mathrm{a}}$ & $257 \pm 14^{\mathrm{b}}$ & $589 \pm 85^{\mathrm{c}}$ \\
& $10-20$ & $62 \pm 7^{\mathrm{a}}$ & $111 \pm 13^{\mathrm{b}}$ & $129 \pm 9^{\mathrm{b}}$ & $315 \pm 14^{\mathrm{c}}$ \\
& $20-40$ & $101 \pm 13^{\mathrm{a}}$ & $206 \pm 33^{\mathrm{a}}$ & $199 \pm 15^{\mathrm{a}}$ & $400 \pm 64^{\mathrm{b}}$ \\
& $40-60$ & $106 \pm 15^{\mathrm{a}}$ & $129 \pm 17^{\mathrm{ab}}$ & $185 \pm 10^{\mathrm{bc}}$ & $246 \pm 35^{\mathrm{c}}$ \\
& $60-100$ & $213 \pm 31^{\mathrm{a}}$ & $268 \pm 29^{\mathrm{a}}$ & $317 \pm 30^{\mathrm{ab}}$ & $431 \pm 62^{\mathrm{a}}$ \\
& Total & $565 \pm 43^{\mathrm{a}}$ & $810 \pm 82^{\mathrm{ab}}$ & $1,087 \pm 50^{\mathrm{b}}$ & $1,981 \pm 203^{\mathrm{c}}$ \\
& & & & & \\
LFC & $0-10$ & $12 \pm 1^{\mathrm{a}}$ & $21 \pm 7^{\mathrm{ab}}$ & $79 \pm 17^{\mathrm{b}}$ & $154 \pm 34^{\mathrm{c}}$ \\
& $10-20$ & $9 \pm 1^{\mathrm{a}}$ & $29 \pm 9^{\mathrm{ab}}$ & $56 \pm 17^{\mathrm{b}}$ & $52 \pm 5^{\mathrm{b}}$ \\
& $20-40$ & $16 \pm 1^{\mathrm{a}}$ & $49 \pm 17^{\mathrm{ab}}$ & $64 \pm 32^{\mathrm{b}}$ & $73 \pm 13^{\mathrm{b}}$ \\
& $40-60$ & $13 \pm 3^{\mathrm{a}}$ & $41 \pm 13^{\mathrm{b}}$ & $25 \pm 1^{\mathrm{ab}}$ & $48 \pm 1^{\mathrm{b}}$ \\
& $60-100$ & $37 \pm 7^{\mathrm{a}}$ & $57 \pm 18^{\mathrm{a}}$ & $50 \pm 4^{\mathrm{a}}$ & $51 \pm 18^{\mathrm{a}}$ \\
& Total & $86 \pm 11^{\mathrm{a}}$ & $197 \pm 58^{\mathrm{ab}}$ & $275 \pm 67^{\mathrm{bc}}$ & $378 \pm 42^{\mathrm{c}}$ \\
\hline
\end{tabular}

Note: Means $( \pm$ SE) at each depth followed by different letters differ significantly $(P<0.05)$ among exclosure ages.

Total soil organic $\mathrm{C}$ storage in the upper $40-\mathrm{cm}$ soil layer accounted for $44 \%, 51 \%, 54 \%$, and $66 \%$ of the total $\mathrm{C}$ storage in active sand dunes, and in 7-, 12-, and 25-year exclosures, respectively. The corresponding percentages were $43 \%, 50 \%, 72 \%$, and $74 \%$ for the light fraction $\mathrm{C}$ storage, respectively. Soil organic $\mathrm{C}$ in the upper $40 \mathrm{~cm}$ contributed $68 \%, 65 \%$, and $75 \%$ of the total soil organic $\mathrm{C}$ increment after grazing exclusion for 7, 12, and 25 years, respectively, whereas the light fraction $\mathrm{C}$ in the upper $40 \mathrm{~cm}$ contributed to $56 \%$, $86 \%$, and $83 \%$, respectively, of the total light fraction $\mathrm{C}$ increment.

For the combined layers of $0-100 \mathrm{~cm}$, the soil organic $\mathrm{C}$ accumulation rates were 35,44 , and $57 \mathrm{~g}$ $\mathrm{C} /\left(\mathrm{m}^{2} \cdot \mathrm{a}\right)$ from 0 to 7,0 to 12 , and 0 to 25 years of livestock exclusion, respectively. The accumulation amounted to 55 and $69 \mathrm{~g} \mathrm{C} /\left(\mathrm{m}^{2} \cdot \mathrm{a}\right)$ from 7 to 12 years and 12 to 25 years, respectively, i.e. the rate of accumulation increased during the later period.

\section{Discussion}

\subsection{Effects of grazing exclusion on soil organic $C$}

The effects of grazing on soil organic $\mathrm{C}$ have been studied in several regions (Shrestha and Stahl, 2008). Some studies reported an increase in soil organic $\mathrm{C}$ in response to grazing exclusion ( $\mathrm{Su}$ et al., 2005; Pei et al., 2008; Steffens et al., 2008), whereas others showed that ungrazed lands exhibited a decline in carbon storage (Weinhold et al., 2001; Reeder and Schuman, 2002), or no change (McIntosh et al., 1997), compared with adjacent grazed areas. Our results are in agreement with $\mathrm{Su}$ et al. (2005) and Pei et al. (2008), who showed that soil organic C increased with increasing exclosure age in degraded lands. This discrepancy in the literature stems from the differences in soil characteristics, degree of degradation associated with grazing, age of exclosures, contribution of manure to the overall nutrient balance in the system, climatic conditions, and original and post-grazing vegetation communities.

Pei et al. (2008) reported that soil organic $\mathrm{C}$ in the top 20 -cm soil layer increased significantly after 2 years of grazing exclusion in a desert steppe in the Alxa region of Inner Mongolia, whereas $\mathrm{Su}$ et al. (2005) observed an insignificant increase of soil organic $\mathrm{C}$ in the upper $15-\mathrm{cm}$ soil layer after 5 years of grazing exclusion in grasslands of the Horqin Sandy Land. The present study showed that total soil organic $\mathrm{C}$ did not increase significantly in the top $10-\mathrm{cm}$ or 20 -cm soil layer after 7 years of grazing exclusion. This demonstrates that the duration of the exclosure may be an important factor, and that more than 7 years might be required for severely degraded lands to show significant recovery. On the other hand, Reeder and Schuman (2002) reported significantly higher soil C in grazed pastures than in non-grazed exclosures. Steffens et al. (2008) reported that the deteriorated topsoil in a semiarid steppe in Inner Mongolia remained unchanged when grazing was excluded for 5 years, and recovered significantly after 25 years of grazing exclusion. This was explained by the grazing pressure that was below a threshold to cause severe degradation, and by the input of manure from grazing animals that improved soil $\mathrm{C}$ storage. These results and our findings show that changes in soil $\mathrm{C}$ associated with livestock grazing exclusion varied with ecosystem, vegetation type, and soil quality prior to the establishment of exclosures. The areas of active sand dunes, which have very low structural integrity and a very low initial organic matter content, might take a long time to show a positive increase in soil $\mathrm{C}$ in exclosures because there are insufficient plants to start with, in order to provide significant input of organic matter, and it takes time to establish a sustainable 
plant community. For example, at our study sites, vegetation cover took 7 years to increase from 3\% to $15 \%$, but in the following 5 years, vegetation cover increased to $42 \%$ (Table 1 ).

Our results showed that the greatest changes in total soil organic $\mathrm{C}$ occurred in the 10 -cm top soil after the removal of livestock. A large proportion (51\% to $66 \%$ ) of soil organic C is stored in the upper $40-\mathrm{cm}$ soil layer in the exclosures. These results are consistent with the observations of Grandy and Robertson (2007) and Shrestha and Stahl (2008), who reported that highly significant changes in total soil $\mathrm{C}$ are primarily observed in the topsoil during the recovery of degraded land.

\subsection{The role of the light fraction in carbon sequ- estration}

The light fraction $\mathrm{C}$ is thought to be an early indicator of soil quality improvement and $\mathrm{C}$ sequestration because it is more sensitive than total soil organic $\mathrm{C}$ to land-use and management practices (Six et al., 2002; Bending and Turner, 2009). Soon et al. (2007) found that the light fraction $\mathrm{C}$ contents showed a marked response to tillage after 4 years, whereas the effect of tillage on total soil $\mathrm{C}$ was not apparent until the $12^{\text {th }}$ year. In the present study, we found that the response of the light fraction $\mathrm{C}$ storage was no more sensitive than the response of total soil $\mathrm{C}$ to the exclosures. Therefore, the light fraction might not be an early indicator of changes in soil organic C storage after grazing exclusion in this case (i.e. related to the soil and vegetation characteristics at the time of the exclusion and the low initial vegetation cover). The light fraction nonetheless played a major role in soil $\mathrm{C}$ sequestration. The light fraction dry matter content was significantly and positively correlated with the total soil organic $\mathrm{C}$ concentration and the silt+clay content (Fig. 3). The dry matter accounted for a very small portion of the total soil mass ( $0.036 \%$ to $0.246 \%$ across all sites), but contributed $21 \%$ to $45 \%$ of the total soil organic C increment in the exclosures. In addition, the light fraction $\mathrm{C}$ accounted for the lowest proportion of the total soil $\mathrm{C}$ in the plots with active sand dunes (15\%), but the proportion increased and stabilized in the 7- and 12-year exclosures (24\% and 25\%, respectively), and then decreased slightly in the 25 -year exclosure
(19\%). This pattern demonstrated that the components of the soil organic matter varied with the exclosure age. In future research, it will be helpful to investigate the mechanisms that determine how the soil organic matter content responds to the exclosure.

\subsection{Potential of grazing exclusion for $\mathbf{C}$ sequestra- tion in the Horqin Sandy Land}

Our results demonstrated a high potential for grazing exclusion to increase soil $\mathrm{C}$ sequestration in the Horqin Sandy Land. The potential C sequestration resulting from the exclosures averaged $57 \mathrm{~g} \mathrm{C} /\left(\mathrm{m}^{2} \cdot \mathrm{a}\right)$ by 25 years after exclosure, although this potential was smaller at younger ages $\left(35 \mathrm{~g} \mathrm{C} /\left(\mathrm{m}^{2} \cdot \mathrm{a}\right)\right.$ between 0 and 7 years after exclosure), and greater at older ages (69 $\mathrm{g} \mathrm{C} /\left(\mathrm{m}^{2} \cdot \mathrm{a}\right)$ between 12 and 25 years after exclosure), before eventual stabilization. Of the area of desertified land in the Horqin Sandy Land, about 9,687 $\mathrm{km}^{2}$ have become heavily or severely desertified by 2000 (Wu, 2005). Given the size of this area and the results of the present study, the amount of carbon sequestered in the $100-\mathrm{cm}$ soil could potentially reach $13.8 \mathrm{Mt}$ in 25 years if this area was to be protected by exclosure and the vegetation be allowed to recover naturally. This amount is equal to $12.8 \%$ of the carbon that Zhou et al. (2008) estimated to have been lost as a result of desertification during the past century (107.53 Mt).

Overall, grazing exclusion in the Horqin Sandy Land has a high potential to sequester C. However, given that the total $\mathrm{C}$ storage in the $100-\mathrm{cm}$ top soil has been estimated to $4,878 \mathrm{~g} / \mathrm{m}^{2}$ in the existing non-desertified grasslands of this region (Zhou et al., 2008), it would take 76 years to fully restore the active sand dunes based on the rate of $57 \mathrm{~g} \mathrm{C} /\left(\mathrm{m}^{2} \cdot \mathrm{a}\right)$. This is clearly a slow process, but our estimates are conservative, since they do not incorporate the $\mathrm{C}$ gain from biomass and litter accumulation (which also play a major role in $\mathrm{C}$ sequestration in a semiarid degraded ecosystem), or consider the contribution of airborne dust deposition to the carbon increase. If these $\mathrm{C}$ sources were to be included in our estimate, the role of the exclosures in carbon sequestration would become much more significant. It is therefore necessary to comprehensively evaluate the effects of the exclosures on ecosystem $\mathrm{C}$ sequestration in this region by including these additional factors. 


\section{Conclusions}

The Horqin Sandy Land is one of the most seriously desertified and ecologically fragile regions in China's agro-pastoral ecotone. The establishment of grazing exclosures in areas with active sand dunes in this region has significantly improved soil $\mathrm{C}$ sequestration. The total soil organic $\mathrm{C}$ increased with increasing exclosure age, but the process was slow, and will take several decades to restore the $\mathrm{C}$ storage to the same levels found in adjacent non-desertified grasslands. The largest increase in $\mathrm{C}$ storage occurred in the $10-\mathrm{cm}$ top soil layer. The soil light fraction played an important role in soil $\mathrm{C}$ sequestration, and its magnitude was strongly and significantly correlated with the total soil organic $\mathrm{C}$ concentration and the silt+clay content. Improving our understanding of the variation in the patterns of response of the light fraction organic matter will benefit from additional research on the

\section{References}

Bending G D, Turner M K. 2009. Incorporation of nitrogen from crop residues into light-fraction organic matter in soils with contrasting management histories. Biology and Fertility of Soils, 45: 281-287.

Conant R T, Paustian K, Del Grosso S J, et al. 2005. Nitrogen pools and fluxes in grassland soils sequestering carbon. Nutrient $\mathrm{Cy}$ cling in Agroecosystems, 71: 239-248.

Cooper A, McCann T, Ballard E. 2005. The effects of livestock grazing and recreation on Irish machair grassland vegetation. Plant Ecology, 181: 255-267.

Dregne H E. 1986. Desertification of arid lands. In: El-Baz F, Hassan M H A. Physics of Desertification. Dordrecht, The Netherlands: Martinus, Nijhoff.

FAO. 2006. FAO/IUSS Working Group WRB, World Reference Base for Soil Resources 2006. World Soil Resources Reports 103. FAO, Rome.

Gong W, Yan X Y, Wang J Y, et al. 2009. Long-term manure and fertilizer effects on soil organic matter fractions and microbes under a wheat-maize cropping system in northern China. Geoderma, 149: 318-324.

Grandy A S, Robertson G P. 2007. Land use intensity effects on soil $\mathrm{C}$ accumulation rates and mechanisms. Ecosystems, 10: 59-74.

Gregorich E G, Ellert B H, Drury C F, et al. 1996. Fertilization effects on soil organic matter turnover and corn residue $\mathrm{C}$ storage. Soil Science Society of America Journal, 60: 472-476.

Hassink J, Whitmore A P, Kubat J. 1997. Size and density fractionation of soil organic matter and the physical capacity of soils to protect organic matter. European Journal of Agronomy, mechanisms by which exclosures enhance soil organic matter content. We indicated that $12.8 \%$ of the ecosystem $\mathrm{C}$ loss that resulted from desertification during the last century could be restored by enhancing $\mathrm{C}$ storage in the soil if grazing was to be excluded from all heavily and severely desertified areas in the Horqin Sandy Land. Our results confirmed that grazing exclusion is an effective way to restore desertified ecosystems, and has a high potential for sequestering soil $\mathrm{C}$ in the semiarid Horqin Sandy Land.

\section{Acknowledgments}

This research was supported by the National Natural Science Foundation of China (40901049; 31060060), the Major State Basic Research Development Program of China (2009CB 421303), and the 'Qing Lan' Talent Engineering Funds of Lanzhou Jiaotong University (QL-08-14A). Our appreciation goes to the anonymous reviewers for their constructive comments.

7: 189-199.

Ibáñez J, Martínez J, Schnabel S. 2007. Desertification due to overgrazing in a dynamic commercial livestock-grass-soil system. Ecological Modelling, 205: 277-288.

ISO. 1998. Soil Quality-Determination of Particle Size Distribution in Mineral Soil Material-Method by Sieving and Sedimentation. Geneva: International Organization for Standardization.

Laycock W A. 1991. Stable states and thresholds of range condition on North American rangelands: a viewpoint. Journal of Range Management, 44: 427-433.

McIntosh P D, Allen R B, Scott N. 1997. Effects of exclosure and management on biomass and soil nutrient pools in seasonally dry high country, New Zealand. Journal of Environmental Management, 51: 169-186.

Murage E W, Voroney P, Beyaert R P. 2007. Turnover of carbon in the free light fraction with and without charcoal as determined using the ${ }^{13} \mathrm{C}$ natural abundance method. Geoderma, 138: $133-143$.

Nelson D W, Sommers L E. 1982. Total carbon, organic carbon and organic matter. In: Page A L, Miller R H, Keeney D R. Methods of Soil Analysis, Part 2, $2^{\text {nd }}$ ed. Madison: American Society of Agronomy, 539-577.

Pei S F, Fu H, Wan C G. 2008. Changes in soil properties and vegetation following exclosure and grazing in degraded Alxa desert steppe of Inner Mongolia, China. Agriculture, Ecosystems \& Environment, 124: 33-39.

Reeder J D, Schuman G E. 2002. Influence of livestock grazing on 
$\mathrm{C}$ sequestration in semi-arid mixed-grass and short-grass rangelands. Environmental Pollution, 116: 457-463.

Shrestha G, Stahl P D. 2008. Carbon accumulation and storage in semi-arid sagebrush steppe: effects of long-term grazing exclusion. Agriculture, Ecosystems \& Environment, 125: 173-181.

Six J, Callewaert P, Lenders S, et al. 2002. Measuring and understanding carbon storage in afforested soils by physical fractionation. Soil Science Society of America Journal, 66: 1981-1987.

Soderstrom B, Part T, Linnarsson E. 2001. Grazing effects on between-year variations of farmland bird communities. Ecological Applications, 11: 1141-1150.

Soon Y K, Arshad M A, Haq A, et al. 2007. The influence of 12 years of tillage and crop rotation on total and labile organic carbon in a sandy loam soil. Soil \& Tillage Research, 95: 38-46.

Steffens M, Kölbl A, Totsche K U, et al. 2008. Grazing effects on soil chemical and physical properties in a semiarid steppe of Inner Mongolia (P.R. China). Geoderma, 143: 63-72.

Su Y Z, Li Y L, Cui J Y, et al. 2005. Influences of continuous grazing and livestock exclusion on soil properties in a degraded sandy grassland, Inner Mongolia, northern China. Catena, 59: $267-278$.

Tan Z, Lal R, Owens L, et al. 2007. Distribution of light and heavy fractions of soil organic carbon as related to land use and tillage practice. Soil \& Tillage Research, 92: 53-59.

Wang X L, Jia Y, Li X G, et al. 2009. Effects of land use on soil total and light fraction organic, and microbial biomass $\mathrm{C}$ and $\mathrm{N}$ in a semi-arid ecosystem of northwest China. Geoderma, 153: 285-290.

Weinhold B J, Hendrickson J R, Karn J F. 2001. Pasture management influences on soil properties in the Northern Great Plains. Journal of Soil and Water Conservation, 56: 27-31.

Westoby M B, Walker B, Noy-Meir I. 1989. Opportunistic management for rangelands not at equilibrium. Journal of Range Management, 42: $2-13$.

Wu W. 2005. Study on Dynamic Evolvement of Modern Sandy Desertification Land in Horqin Sandy Land. Beijing: Ocean Press, $189-226$.

Zhou R L, Li Y Q, Zhao H L, et al. 2008. Desertification effects on C and $\mathrm{N}$ content of sandy soils under grassland in Horqin, northern China. Geoderma, 145: 370-375. 